\title{
COMENTARIO
}

\section{Imaginar la soberanía alimentaria y las oportunidades para las agriculturas del México globalizado*}

\author{
Guadalupe Rodríguez Gómez
}

El derecho a la alimentación es un derecho universal. Implica que toda persona — mujer, hombre o niño-debe tener acceso a alimentos en todo momento [...] que sean suficientes en términos de calidad, cantidad y variedad para satisfacer sus necesidades, que estén libres de sustancias nocivas y sean aceptables para su cultura.

Pacto Internacional de Derechos Económicos, Sociales y Culturales, ONU, 1966 Signado y ratificado por 156 países en $1976^{1}$
El [Programa] Hambre Cero está promoviendo el derecho humano a la alimentación adecuada y a la seguridad alimentaria y nutricional por medio del fortalecimiento de la agricultura familiar, del estímulo a la formación de cooperativas [de agroproductores], de la creación de infraestructura, de la generación de empleos formales y del acceso a una adecuada nutrición.

Gobierno Federal de Brasil, $2005^{2}$

\footnotetext{
1 "El derecho a la alimentación”, Día Mundial de la Alimentación, TeleFood 2007, nota informativa FAO (en <http://www.fao.org:80/wfd2007/ index_wfd2007.html?L=2>). El artículo in extenso del Pacto apunta lo siguiente: "Los Estados Partes en el presente Pacto, reconociendo el derecho fundamental de toda persona a estar protegida contra el hambre, adoptarán, individualmente y mediante la cooperación internacional, las medidas, incluidos los programas concretos, que se necesiten para: a) mejorar los métodos de producción, conservación y distribución de alimentos mediante la plena utilización de los conocimientos técnicos y científicos, la divulgación de principios sobre la nutrición y el perfeccionamiento o la reforma de los regímenes agrarios de modo que se logren la explotación y la utilización más eficaces de las riquezas naturales; b) asegurar una distribución equitativa de los alimentos mundiales en relación con las necesidades, teniendo en cuenta los problemas que se plantean tanto a los países que importan productos alimenticios como a los que los exportan" (véase artículo $11 \mathrm{en}<\mathrm{http} / /$ www.unhchr.ch.ch/spanish/html/menu3/b/a_cescr_ sp.htm>).

${ }^{2}$ Governo Federal, FOME Zero-Balanço dos programas a ações, octubre de 2005, cit. en Da Silva et al., 2006.
}

Imagining Food Sovereignty and the Agricultural Opportunities of Globalized Mexico

GUADALUPE RODRÍGUEZ GOMEZ: Centro de Investigaciones y Estudios Superiores en Antropología Social-Occidente,

Guadalajara, México

rogo8512@hotmail.com

* Agradezco a Jorge Alonso, Camila Pascal y Cynthia Hewitt su confianza y solidario apoyo.

Desacatos, núm. 25, septiembre-diciembre 2007, pp. 101-114. 
[Con el incremento de los precios de los granos a nivel mundial] creo que enfrentamos una crisis alimentaria [...] Tenemos que trabajar en ello y empezar a producir nuestros propios alimentos [en el caso de África].

Kofi Annan, ex secretario general de la ONU, 2007

$\mathrm{L}$ a autosuficiencia alimentaria de México, comenta Jorge Zepeda Patterson, se ha ido perdiendo de manera irresponsable en las últimas décadas ${ }^{3}$. Las importaciones de granos básicos — afirma el analista— constituyeron 29\% del consumo nacional en el periodo 2004-2006. En línea similar — agrega—, las importaciones de oleaginosas alcanzaron un promedio de $91 \% \mathrm{du}-$ rante el mismo periodo, mientras que $26 \%$ del consumo interno de carnes rojas se satisfizo también mediante importaciones. Para el cierre de este año se prevée que la importación de 3.5 millones de toneladas de trigo subsane la deficiente producción nacional, la cual desde hace años ha no logra satisfacer la demanda interna ${ }^{4}$. Como hemos leído en este número, Humberto González y Alejandro Macías consideran que éstas son también algunas de las condiciones por las cuales en México se debe hacer referencia a la vulnerabilidad alimentaria y, al hacerlo, dejar de lado el paradigma de la seguridad alimentaria. La discusión, considero, debe ir más allá de este debate.

Hace unos días José Luis Calva argumentó que los precios de la canasta básica en nuestro país se han venido incrementando de forma paulatina — yo añadiría preocupante- ${ }^{5}$. El economista, con base en información del Banco de México, señala que los precios se dispararon

\footnotetext{
3 “'Gasolinazo', una reacción al pánico”, El Universal, domingo 7 de octubre de 2007.

4 "Provocan especuladores el alza de trigo y pan: $\mathrm{CCI}$ ", en $<\mathrm{http} / /$ noticias.prodigy.msn.com/nacional/articulo.aspx?cp-documentid $=5473995>$, noticia recabada el 23 de septiembre de 2007. En relación con la caída de la producción nacional en el periodo de vigencia del Tratado de Libre Comercio de América del Norte, recordemos que González y Macías apuntan un decrecimiento de $-28.6 \%$ en la producción nacional de trigo. Esta drástica caída sólo es superada por el decrecimiento de $-57.2 \%$ en el caso del arroz y de $-44.6 \%$ en la producción de frijol. 5 "Burbuja inflacionaria", El Universal, jueves 4 de octubre de 2007.
}

$0.62 \%$ respecto a la segunda quincena de agosto, siendo ésta el alza más elevada en periodos similares durante los últimos seis años. De manera específica —continúa Calva-, los precios agropecuarios crecieron 3.27\%, lo cual explica la cifra de $45.1 \%$ de la inflación agregada quincenal. Si a ésta se suma la incidencia de los alimentos procesados tenemos que 53.2\% de la inflación agregada en la primera quincena de septiembre de 2007 obedece al alza en el costo de los alimentos. Es interesante apuntar que, para este especialista, gran parte de la explicación del aumento de los precios de la canasta básica o, mejor aún, de la "carestía de alimentos" que enfrentamos la mayoría de los mexicanos, radica hoy en procesos externos y, en cierta medida, ajenos a nuestro país. Y la piedra angular de éstos — añade Calva, basándose en argumentos parecidos a los del Centro de Estudios Económicos del Sector Privado (CEESP) — es el aumento en los precios que reciben los productores de básicos y oleaginosas en las principales potencias agropecuarias del mundo ${ }^{6}$. Para el economista, dos son las explicaciones de dicha escalada: a) el incremento de la demanda de alimentos "en las superpobladas y superdinámicas economías emergentes de Asia”, y b) el agudo re-direccionamiento de la producción del maíz de alimento y/o forraje a biocombustible que se ha dado en los últimos meses a nivel mundial7.

\footnotetext{
6 "CEESP: se deterioraron expectativas de inflación por el aumento de precios", La Jornada, lunes 8 de octubre de 2007.

7 Es interesante notar que los analistas estadounidenses consideran que uno de los cambios más significativos del mercado de alimentos mundial en los últimos treinta años es el disparo en los precios y el agudo incremento en la demanda de granos; cambio que podría mantenerse durante una década más (Dow Jones Newswires, 28 septiembre de 2007). Los efectos de estas agresivas y rápidas dinámicas lo están resintiendo consumidores de países ricos y pobres, a la par que los agroproductores y las fuertes corporaciones nacionales e internacionales. Para estos analistas dichos cambios obedecen: 1) al auge en las economías de Asia y Latinoamérica, que conlleva un incremento en la demanda de alimentos por causa de un crecimiento en el flujo de capital, lo que permite un gasto mayor en estos bienes; 2 ) a la fuerte inyección de recursos/subsidios que Estados Unidos ha destinado en los últimos meses como incentivo para que se incremente el grupo de productores dedicados al maíz y a la soya como biocombustibles — y ya no como alimentos ni como forrajes-; 3) la tendencia en otros países, como México, a cambiar la vocación de la agricultura de alimentos y forrajes hacia la de producción de energéticos verdes; 4) la continuidad en la tendencia a que se consuman a nivel mundial más granos para producir alimentos, forrajes y biocombustibles, con lo cual pareciera alcanzarse la mayor reducción de las reservas de granos en relación con su
} 


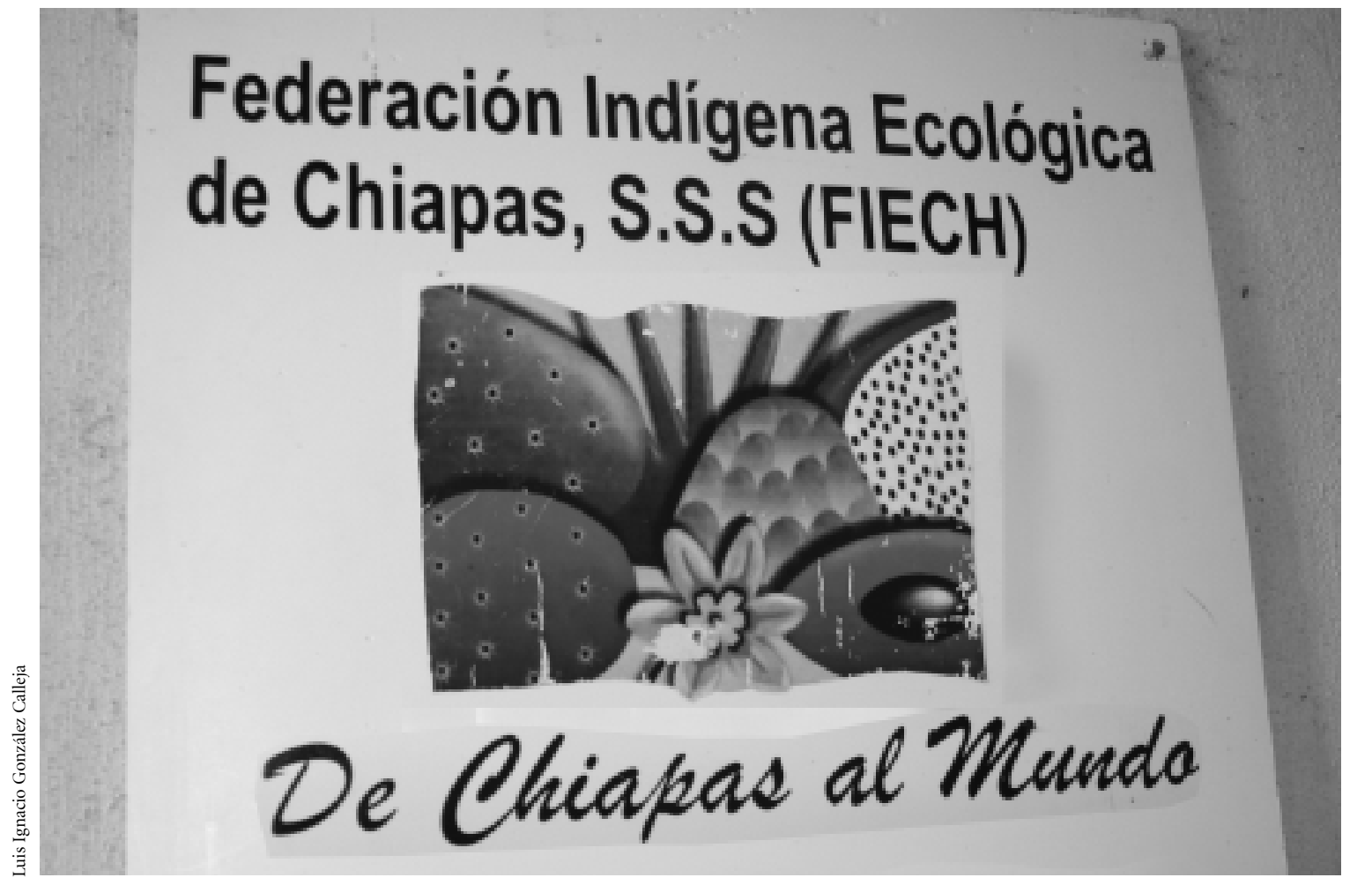

El comercio alternativo de café orgánico.

Sin poner en duda la explicación de $\mathrm{Calva}^{8}$, rescato el corolario de su análisis: "la carestía nos pega fuertemente por la tremenda dependencia alimentaria de México" (ibid.). En una línea de análisis semejante a la de Zepeda Patterson, González y Macías, y Cynthia Hewitt, reconocen la gravedad de los efectos resultados de las formas específicas que han caracterizado la fluida objetivación de la globalización neoliberal de nuestro país desde la década de 1980 a la fecha. Uniéndose al resto de los especialistas aquí citados, llaman a que se diseñen e implementen políticas agrícolas adecuadas por ser éstas el único

consumo registrado desde 1970. Lo anterior inquieta a grupos de poder, analistas, funcionarios de agencias estatales y multilaterales, ya que parecen ser señales no sólo de una mayor vulnerabilidad de los países, sino también del incremento del hambre y la desnutrición en el mundo.

${ }^{8}$ Este ejercicio va más allá del objetivo de este ensayo. mecanismo para resolver la dependencia alimentaria en tanto problema estructural de nuestro país.

La discusión precedente me ha permitido introducir los hilos con los que intento tejer este ensayo: a) plantear nuevamente la necesidad de que el Estado mexicano privilegie la seguridad alimentaria (que no autosuficiencia, pero sí independencia) y, para ello, se reconfigure el marco jurídico de forma tal que se incluya en su agenda, como una prioridad nacional, la elaboración de una ley ética y democráticamente consensuada de soberanía alimentaria, sustentada ésta en el derecho que tenemos todos los ciudadanos mexicanos de acceso a alimentos nutritivos y de calidad, independientemente de las diferencias de clase, estatus y poder que nos distinguen (Rodríguez Gómez, 2006); b) invitar a que se considere la importancia de incluir en este ejercicio los derechos humanos en función del papel que de manera creciente se les ha reconocido y otorgado en la práctica en relación con la erra- 
dicación del hambre y de la pobreza, así como al fortalecimiento de desarrollos sostenibles en el mundo 9 ; y c) proponer una vez más la pertinencia de buscar el reconocimiento, la revalorización material y simbólica, así como el fortalecimiento equitativo de la diversidad de agriculturas que se practican en nuestro México y, a la par, de los bienes agroalimentarios que éstas generan, ya que dichos procesos se acompañarán de oportunidades de empleo, salud, nutrición y condiciones de vida digna para los ciudadanos rurales, en particular, y de nuestro país, en general (Rodríguez Gómez, 2006).

Inicio este ejercicio retomando, críticamente, las reflexiones y contribuciones analíticas e interpretativas que nos presentan los trabajos de los distintos estudiosos que constituyen este volumen de Desacatos. De ahí paso a imaginar la soberanía alimentaria de México, enmarcada en lo que considero las oportunidades para las agriculturas de nuestro país.

\section{EL COMENTARIO}

La arqueología de las cualidades dialógicas, procesuales y polisémicas que han caracterizado a la seguridad alimentaria en tanto forma discursiva cardinal de las políticas agroalimentarias, de combate al hambre y a la desnutrición y, más recientemente, a la pobreza en el mundo desde finales de la Segunda Guerra Mundial hasta hoy, es críticamente documentada por Humberto González en la presentación de este número de la revista Desacatos. En uno de los artículos subsiguientes, el especialista, en coautoría con Alejandro Macías, resalta las limitaciones que conlleva el uso del concepto de seguridad alimentaria para aprehender, caracterizar y explicar las dinámicas históricas de las recientes políticas agrícolas de nuestro país. En este ensayo los estudiosos proponen y, en consecuencia, llevan a cabo el ejercicio analítico del caso mexicano en el marco de la vulnerabilidad alimentaria, en tanto forma alterna más ad hoc y, especialmente, menos

9 "El derecho a la alimentación, hacerlo realidad", World Food Day 2007, Inicio, en: <http://www.fao.org/wfd207/index_wfd2007.html?L=2>. ambigua, según afirman, que la de seguridad alimentaria. Esto les faculta a concluir remarcando que su estrategia metodológica les permitió evidenciar sólidamente la creciente vulnerabilidad alimentaria que ha distinguido al México globalizado a raíz de la dinámica y multivocal adopción del paradigma neoliberal. Al abrir su ensayo sobre el recuento histórico de los obstáculos al desarrollo rural en México, Cynthia Hewitt coincide en reconocer este logro del trabajo presentado por González y Macías.

La propuesta interpretativa de González y Macías se sustenta en el replanteamiento de "vulnerabilidad alimentaria" que presentaron Blaikie et al. en 1996. La singularidad del ejercicio que realizaron los autores aquí comentados consiste en privilegiar tres hilos conductores para el estudio de la vulnerabilidad alimentaria de México a la luz de la revisión histórica de las políticas económicas llevadas a cabo durante las últimas décadas. Para ello se sustentaron en los datos "duros" de agencias internacionales y nacionales. Los tres hilos conductores son: 1) las condiciones agropecuarias y económicas de producción que tienen que ver con el abasto suficiente (o no) y oportuno (o no) de alimentos inocuos; 2 ) las condiciones medioambientales que conllevan el uso sustentable de los recursos naturales a corto y largo plazo; y 3 ) las condiciones sociales de la población que padece desnutrición y hambre en nuestro país o que pueden, en su defecto, potencialmente padecerlas. El ejercicio resulta interesante en tanto que no solamente logra articular el riesgo alimentario de un país en vías de desarrollo, como lo es México, sino que este riesgo lo sitúan los autores como fruto de la interconexión de distintos macro y micro procesos, tales como: la dependencia creciente por parte del Estado del mercado mundial para satisfacer las demandas alimentarias básicas de su población; los efectos negativos que acompañan a la producción de alimentos que no toma en cuenta la degradación ambiental; el descuido público y privado de los recursos naturales; la gradual pérdida del patrimonio genético de México - particularmente en el caso de los granos básicos-

Es interesante notar que en el artículo previo al de González y Macías, Archanjo et al. llevan a cabo un ejercicio semejante al de los autores ya comentados. El objetivo de éste fue aprehender las características de la 
producción y de la disponibilidad de alimentos en Latinoamérica y el Caribe, poniendo especial atención al caso de Brasil. Si bien este objetivo es suficiente para diferenciar el trabajo de los especialistas brasileños del de los colegas mexicanos, dos más son las características que distinguen dichos ensayos. Primero, Archanjo et al. centran su ejercicio en el abordaje de las políticas públicas de Brasil en torno a la alimentación y la nutrición. Segundo, el marco interpretativo que guía el análisis es, a diferencia del de González y Macías, el de seguridad alimentaria y nutricional. En esta misma línea, y fuertemente influidos por los marcos jurídicos, objetivos y programas del Estado brasileño y de la Organización de las Naciones Unidas para la Agricultura y la Alimentación (FAO), Archanjo et al. suman a su ejercicio, como herramientas analíticas: a) el llamado a considerar los principios del derecho humano a la alimentación saludable y adecuada y a la soberanía alimentaria; b) la pertinencia de tomar en cuenta analíticamente las disparidades para tener acceso de forma equitativa a alimentos nutritivos de los distintos sectores de la población ; y c) la necesidad de adecuar lo anterior a la promoción de desarrollos sustentables acordes con la heterogeneidad de realidades que conforman el Brasil rural. Así, los estudios de caso de Brasil y México desde perspectivas distintas ilustran, primero, la específica heterogeneidad de ambos países, al tiempo que dan cuentan de la complejidad que conlleva abordar analíticamente la vulnerabilidad alimentaria a la que aluden González y Macías y la seguridad alimentaria y nutricional que enmarca teórica y metodológicamente el estudio de los brasileños.

La diferencia más significativa entre ambos estudios es que dejan ver que Brasil, a diferencia de México, cuenta ya con una ley de soberanía alimentaria. Ésta, como bien señalan Archanjo et al., es relevante no sólo porque por primera vez incluye el derecho humano a la alimentación y el combate al hambre y a la pobreza como puntos centrales de la agenda nacional del Estado brasileño, sino también porque objetiva una propuesta de política integral de seguridad alimentaria, de rescate y apoyo a la agricultura a pequeña escala, así como de combate al hambre y a la desnutrición con la participación tanto del Estado como de la sociedad civil. En el caso de México, la propuesta de una ley de esta naturaleza quedó desafortunadamente atrapada en las telarañas de intereses encontrados y conflictivos y en los ambiguos rejuegos de poder entre la Cámara de Diputados y la de Senadores del sexenio pasado (2000-2006), a pesar de que ya para entonces la democracia mexicana había adquirido cierta centralidad en tanto práctica discursiva en la vida del país.

Ambos ensayos coinciden en evidenciar dos procesos interrelacionados: a) la creciente preeminencia de la agricultura empresarial de exportación en detrimento de las agriculturas de granos básicos y, en particular, de lo que se conoce como agricultura familiar, tanto en México como en Brasil, punto sobre el que bordaré en la siguiente sección; y b) la concomitante desigual distribución de recursos públicos y beneficios de la comercialización, ya que los Estados en cuestión canalizan de manera más eficiente y abundante apoyos (financieros, tecnológicos, de información, entre otros) a los grandes productores, dejando prácticamente de lado a quienes producen en menores escalas o, en términos tecnocráticos, son "menos eficientes, productivos y, por ende, competitivos", lo cual, en ambos países, ha conllevado el agudizamiento de la polarización así como de la desigualdad socioeconómica y de poder entre los productores agropecuarios y el hecho de que se acentúa la concentración de "agricultura competitiva” en ciertos grupos de productores y regiones.

En esta línea, el ensayo de Hewitt es particularmente iluminador al ilustrar las formas en las que se ha reproducido históricamente en México la práctica de privilegiar la canalización de apoyos públicos a los grandes productores y/o fuertes empresas agroalimentarias. Este proceso no sólo ha demostrado ser un obstáculo al desarrollo socioeconómico equitativo — señala la estudiosa—, sino que explica el constante fortalecimiento de estos miembros de los grupos dominantes a costa de la pérdida de empoderamiento de la mayoría del resto de los agroproductores, así como a la implementación de nuevas formas de control de los pequeños y medianos productores por parte de los grandes productores y de las fuertes empresas agroalimentarias $y / o$ agroindustriales nacionales y transnacionales que operan en el país. Los estudios sobre Brasil y México aprehenden también críticamente las 


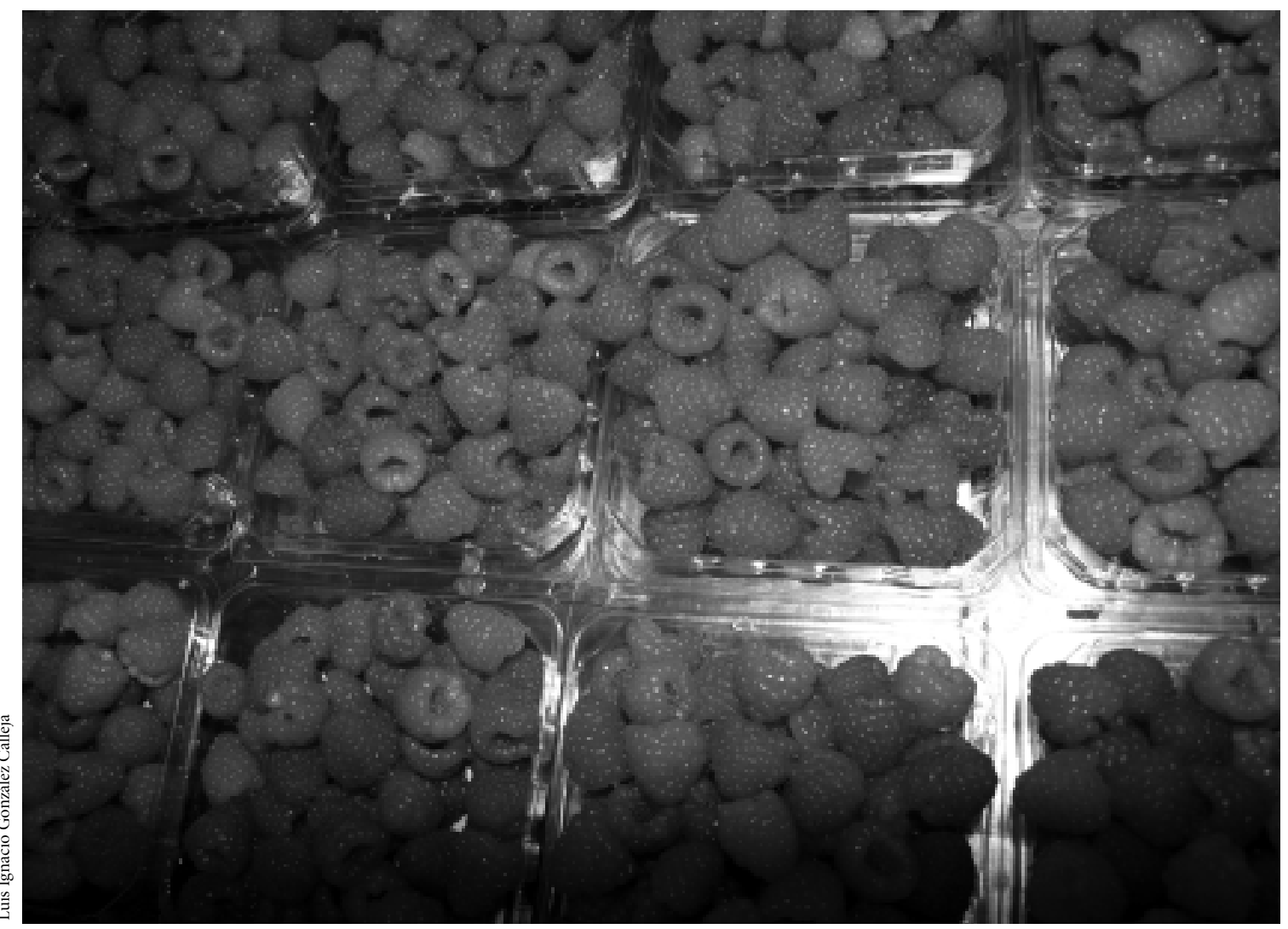

Alimentos para consumidores de altos ingresos.

marcadas desigualdades que se dan al interior de los países estudiados en lo que se refiere a producción, comercialización, distribución y consumo de alimentos. Aluden, además, a las dificultades que existen para el acceso a suficiente cantidad de alimentos de calidad por parte de un importante número de ciudadanos en ambos países.

De forma por demás significativa, ambos trabajos evidencian la creciente y preocupante dependencia de los países en desarrollo - particularmente en lo relativo a alimentos básicos—de las dinámicas, y no por ello menos complejas, condiciones de los mercados globales. En los dos ejercicios se remarca atinada y sólidamente el hecho de que los mercados internacionales de alimentos están férreamente controlados tanto por las grandes potencias alimentarias como por las fuertes corporaciones transnacionales de alimentos frescos y procesados. De hecho, en el caso mexicano, González y Macías exponen los riesgos que conlleva la creciente dependencia al mercado estadounidense que ha ido tejiendo y fortaleciendo nuestro país en las tres últimas décadas: tanto en lo que se refiere al abasto de alimentos básicos provenientes de manera mayoritaria de Estados Unidos, como al hecho de que la producción agroalimentaria de exportación nacional se destina cada vez más (en términos de mayor volumen y variedad de productos alimentarios) a satisfacer la cambiante - a la vez que estacional - demanda de mercados de alimentos frescos y procesados de los consumidores estadounidenses.

De igual manera es preocupante — como apuntan los distintos trabajos citados y, en particular, el ensayo de Archanjo et al. - el vertiginoso uso de poder de las multinacionales agroalimentarias y agroindustriales con res- 
pecto a la manipulación de la calidad de la nutrición de los alimentos, por un lado, y por el otro, a la información que en estas dimensiones se les permite (o no) conocer a los consumidores del mundo. Esto tiene como corolario un ejercicio más de control por parte de los potentes agentes antes mencionados sobre las legislaciones de los organismos supraestatales (i.e., Organismo Mundial de la Salud, 200410), así como sobre los marcos jurídicos de los Estados nacionales mismos. Estas tecnologías de poder de las que echan mano las transnacionales para evadir las responsabilidades que les corresponden en lo que se refiere a dejar saber a los consumidores la dudosa (o no) calidad y contenido nutricional de los alimentos se traducen en individualizar la responsabilidad de los riesgos alimentarios en el nivel de los ciudadanos particulares. Así, la toma de responsabilidad individual por la alimentación de dudosa calidad o poco nutritiva se contrapone a la noción de la garantía de los derechos humanos y sociales como responsabilidad conjunta de la sociedad y del Estado. He aquí, una vez más, la pertinencia de incluir los derechos humanos como principios configuradores de las políticas agroalimentarias y nutricionales, al menos en lo que al caso de México se refiere. En otro tenor, pero en línea similar, estos ejercicios de poder de las corporaciones multinacionales de alimentos atentan de facto contra los marcos jurídicos y, en consecuencia, actúan en detrimento de las soberanías alimentarias de la mayoría de los países — quizá con excepción (al menos parcial) de Estados Unidos y la Unión Europea-. Estos ejercicios de poder los llevan a cabo estos agentes socioeconómicos y políticos al imponer de formas poco transparentes, con poco sentido ético y de justicia, criterios y formas de definir, medir y vigilar los estándares y prácticas de la calidad y de la nutrición (Rodríguez Gómez, 1998).

Estos dos artículos, a la par del ensayo de Cynthia Hewitt, ilustran de manera adecuada las formas en las que México y Brasil se pueden considerar casos emblemá-

10 Organización Mundial de la Salud (OMS), "OMS lança estratégia global antiobesidade", Folha de São Paulo, 22 de mayo de 2004, Sao Paulo, p. A11, cit. en Archanjo et al. ticos de complejos y conflictivos - $\mathrm{O}$ al menos ambiguos - procesos de "in-seguridad alimentaria" en Latinoamérica. Pareciera que estos tres especialistas mexicanos entienden la inseguridad alimentaria como una concomitante de la extensa y bien abordada vulnerabilidad alimentaria que caracteriza al reciente desarrollo agropecuario de México, en términos de la propuesta interpretativa de González y Macías. Por esto, señalan que el modelo de desarrollo que ha seguido el México globalizado de corte neoliberal ha llevado al país a condiciones de inseguridad alimentaria. De manera atinada pregunta Hewitt si no existe la posibilidad de que se reconfigure el modelo imperante de desarrollo de nuestro país precisamente por la vulnerabilidad que conlleva estar tan estrechamente vinculados a los mercados mundiales, ya que éstos son y han sido históricamente, afirma la especialista, altamente inestables. Esto permite a la antropóloga abrir el espacio para llamar la atención en torno a la pertinencia de diseñar y poner en marcha un modelo de desarrollo alternativo tal que se sustente en la revaloración del papel del sector agropecuario en la seguridad alimentaria de nuestro país. Retomaré este señalamiento en la sección siguiente por considerarlo central para imaginar la soberanía alimentaria de México.

En contraste y con cierto grado de complementariedad con las propuestas de los mexicanos, Archanjo et al. conciben la inseguridad alimentaria como la falta de garantías de acceso a alimentos adecuados nutricional y culturalmente que experimentan el grueso de los ciudadanos en Latinoamérica y, en particular, en Brasil. En línea similar, José Graciano da Silva, Maya Takagi y Mauro Eduardo del Grossi, otros tres estudiosos del tema en Brasil, consideran que la inseguridad alimentaria es una forma discursiva que abarca un abanico amplio de condiciones relacionadas con las dimensiones de calidad y dignidad en lo que se refiere al consumo de alimentos ${ }^{11}$. Ambos principios deben estar en estrecha relación con

\footnotetext{
${ }^{11}$ Justamente por ello —insinúan estos especialistas— es que tales alimentos no pueden ser aquellos que conlleven la obesidad y/o la obesidad-con-desnutrición, la desnutrición o las enfermedades cardiovasculares, como sucede crecientemente en México y en Estados Unidos (Da Silva et al.,2006).
} 
el acceso equitativo a alimentos nutritivos y a su consumo efectivo, sostienen estos colegas. En consecuencia, deben necesariamente acompañar la búsqueda de seguridad alimentaria. Argumentan, de forma complementaria, que la inseguridad alimentaria es una forma cultural que permite plantear políticas preventivas para evitar que las familias lleguen al estado de desnutrición y, al hacerlo, se torna en un concepto más amplio que aquel que se ciñe al problema del hambre y de la pobreza (Da Silva et al., 2006: 3-6).

Llevando más allá estos críticos planteamientos, retomo la propuesta de Maxwell y Slater (2003, cit. en Da Silva et al., 2006: 6), la cual identifica al sistema alimentario mundial como el objeto central de las nuevas políticas de seguridad alimentaria y nutricional. Es decir, no se puede hablar simplemente de políticas alimentarias puesto que de hacerlo se restringe la discusión y las acciones correspondientes sólo al suministro de alimentos en momentos de crisis. En todo caso - aclaran Da Silva et al. (2006: 6-7)—, ambas políticas deben concebirse de forma complementaria porque ambas son, en último término, necesarias. Esto obedece a que la primera se asocia con la esfera de consumo que, en el nivel interno, garantice el acceso a la alimentación de calidad sin excluir a ningún ciudadano de un país, mientras que la segunda tiene que ver con las formas de regulación de los sistemas alimentarios nacionales y/o mundial. Más importante es aún rescatar el hecho de que para estos analistas la atención debería enfocarse en la configuración del sistema alimentario mundial en sí misma, ya que es precisamente ésta la que explica - al tiempo que re-produce y re-significa, añado - las desigualdades e injusticias en la producción, distribución y consumo de alimentos que le distinguen en distintos momentos históricos. El carácter inequitativo y, por ende, injusto del sistema alimentario obedece - valga la pena recordar - a las desiguales (mas siempre cambiantes-fluidas-ambiguas-conflictivas) relaciones/alianzas y rupturas de poder que se dan entre los distintos países que lo conforman.

En otro tenor, más de forma por demás ilustrativa de la especificidad de estos procesos, los artículos de González y Macías y de Hewitt nos permiten apreciar el estrechamiento de la dialógica vinculación, siempre conflicti- va y desigual, de México al sistema alimentario mundial particularmente desde la década de 1990 a la fecha, aclara Hewitt. Retomando la discusión de esta estudiosa, resulta innegable que la definición y explicación de la seguridad alimentaria (y, simultáneamente, de la in-seguridad alimentaria) de México va más allá de nuestra relación con el sistema agroalimentario global. Ésta tiene que ver de manera particular — afirma atinadamente la especialista - con la pérdida de centralidad que ha experimentado la producción agropecuaria en las estrategias del Estado relativas al desarrollo nacional. El paradigma que hoy impera ha relegado la función de estas actividades a las de meras generadoras de divisas que contribuyan al saneamiento de la balanza de pagos, que garantice a su vez un libre flujo de capital por el país. Consecuentemente, señala Hewitt, la seguridad alimentaria descansa en la disponibilidad de divisas que permita al Estado tener acceso (o no) al mercado mundial de agroalimentos para satisfacer la demanda nacional de los mismos. Coincido con la estudiosa al considerar que esta estrategia explica la recurrente, y por ende preocupante, pérdida de valor social, simbólico, material y político de las agriculturas y alimentos de México

\section{OPORTUNIDADES POR IGUAL PARA LAS DISTINTAS AGRICULTURAS DE MÉXICO: UN PASO A LA SOBERANÍA...}

Cierro este comentario invitándonos a reflexionar sobre el papel que desempeña y debe desempeñar el rescate, promoción y la revalorización, en términos equitativos y lo más incluyentes posibles, de las diversas agriculturas que se han dado en México en las últimas décadas. Lo hago a la luz de la tan necesaria reconstrucción de nuestra soberanía alimentaria a corto, mediano y largo plazo, enmarcada ésta en el fluido, poroso, ambiguo, conflictivo, desigual e incluyente/excluyente proceso de globalización a la neoliberal que hemos vivido desde la década de 1980 y en la más reciente tendencia a la democratización del país. Considero que este ejercicio debe tener como piedra angular un llamamiento a la revisión crítica de nuestras políticas agroalimentarias y económicas en el 
marco del derecho a la alimentación que tenemos todos en tanto ciudadanos mexicanos, indistintamente de las diferencias de clase, estatus y poder que nos distinguen. Para ello deben seguirse las líneas que marca el Pacto Internacional de Derechos Económicos, Sociales y Culturales de 1976 y, simultáneamente, el abordaje intersecto$\mathrm{rial} /$ muldisciplinario (integral) que debe caracterizar este ejercicio ${ }^{12}$. Debe conllevar, simultáneamente, la elaboración consensuada de manera ética y democrática de una ley de soberanía alimentaria que tenga como cimiento el reconocimiento y la operacionalidad del derecho que tenemos todos los mexicanos por igual al acceso a alimentos de calidad. Extiendo la invitación a que se diseñen proyectos integrales para el fortalecimiento de los desiguales sistemas locales y regionales de producción y consumo de alimentos y para la creación de nuevos mercados y, de forma simultánea, para el fortalecimiento y la vinculación más justa y eficiente entre los ya existentes tanto como entre éstos y los distintos productores y consumidores.

Este llamado propone que el incremento del valor material, político y simbólico de las diversas agriculturas de México así como de los bienes agroalimentarios se debe insertar en una política económica de derechos, la cual se articule con estrategias de fomento productivo y de generación de empleos formales. De esta forma, este llamado a la re-valorización y, por ende, a la creación de oportunidades para nuestras agriculturas deberá acompañarse de posibilidades de empleo formal y de vida dig-

\footnotetext{
12 Para conocer este documento y las subsecuentes revisiones, modificaciones y adecuaciones para la puesta en práctica de lo propuesto en él, es necesario consultar, además, los siguientes documentos de la Organización de las Naciones Unidas (ONU) y de la Organización Mundial para la Agricultura y la Alimentación (FAO): 1) Pacto Internacional de Derechos Económicos, Sociales y Culturales, Adoptado y abierto a firma, ratificación y adhesión por la Asamblea General en su resolución 2200a (XXI), del 16 de diciembre de 1966, el cual entró en vigor el 3 de enero de 1976, en conformidad con el artículo 27;2) Observación General 12 del Comité de Derechos Económicos, Sociales y Culturales, 1999; y 3) las Directrices Voluntarias que elaboró el Consejo de la FAO en el 2004 para sustentar las Directrices sobre el derecho a la alimentación (i. e., "Realización Progresiva del Derecho a una Alimentación Adecuada en el contexto de la Seguridad Alimentaria Nacional"). Todas estas revisiones y modificaciones se han realizado acordes a las cambiantes condiciones de los distintos países firmantes y del mundo.
}

na, que pueden: a) coadyuvar a la promoción de los derechos humanos y de desarrollos sostenibles en las distintas localidades y regiones del país, $y$, simultáneamente, b) incidir en amainar la migración laboral así como la inequidad rural y rural-urbana que caracterizan al México del siglo XXI.

Esto supone, además, una apuesta en particular por nuestros pequeños y medianos agroproductores. Hace décadas que se argumenta que el "tradicionalismo campesino", entendido éste como tozuda oposición al cambio que conlleva la formación de un Estado mexicano global-neoliberal, amarra a los agroproductores a la ineficiencia, la baja productividad, a una rentabilidad cuestionable y a una dudosa contribución a la construcción del México moderno, como bien apunta Cynthia Hewitt en su artículo en este número de Desacatos. Sin embargo, hoy, al igual que lo afirmó en la década de $1970 \mathrm{Ar}-$ turo Warman:

los campesinos siempre han estado presentes para contradecir, para denunciar la injusticia y defender su derecho a cultivar la tierra y conservar su fruto. Los campesinos siguen estando ahí, contradiciendo con su presencia y con su quehacer a los nuevos explotadores, los que promueven el "desarrollo y la modernización” basada en la explotación que se impone por la violencia y se justifica con la soberbia del poderoso y a veces con su estupidez (Warman, 1976: 17).

Hoy, ante las incertidumbres, los retos y las oportunidades que representa el año 2008 para los campesinos ${ }^{13}$, nuestras agroproductores siguen estando aquí: en los diversos espacios del México rural, del urbano y en los intersticios de ambos, y también muchos de ellos como mano de obra barata en Estados Unidos.

Algunos de estos actores, dejando de lado las organizaciones históricas de corte corporativista y vinculadas ya

\footnotetext{
${ }^{13}$ El 1 de enero de 2008 finalizan las "prórrogas proteccionistas" de que gozaban el maíz, el frijol y la leche por los Acuerdos del Tratado de Libre Comercio de América del Norte. Los gobiernos de México y de Estados Unidos no contemplan la posibilidad de renegociar el TLC en lo que toca a dichos productos agroalimentarios, a pesar de ser los que más resentirán la apertura del comercio con nuestros socios de América del Norte.
} 
a diversas cadenas agroalimentarias, se han organizado para comercializar su producto en colectivo y responder a las exigencias de calidad, eficiencia y competitividad impuestas por los distintos mercados domésticos y globales. Estas respuestas individuales-colectivas se dan al adaptar, resignificar y aprovechar: a) las oportunidades e imperativos del Estado neoliberal, así como b) los retos y demandas que les impone el tener que estar vinculados a mercados diferencialmente globalizados. Frente a la desincorporación de las paraestatales, otros agroproductores han optado, asimismo, por organizarse para juntos abatir costos de producción y mejorar las condiciones de financiamiento y mercadeo para sus granos. Otros más se han asociado para aprovechar los nichos de mercado recién abiertos a productos orgánicos; alimentos del comercio justo; productos que el Estado ha dotado con el reconocimiento de "marca colectiva"; alimentos frescos y procesados distinguidos recientemente con el sello "México calidad suprema"; aquellos que han sido incorporados al reconocimiento que otorga el movimiento "Slow Food", o los que han logrado obtener la protección de la denominación de origen en México y en el mercado global.

Paradójicamente, la gran mayoría de los pequeños y medianos agroproductores lucha de manera individual ante los nuevos y dinámicos contextos macro y microeconómicos manteniendo, al tiempo que reformulan y resignifican, ideas y prácticas agropecuarias heredadas. En nuestro país, a pesar de las dinámicas y contradicciones internas y las relacionadas con el contexto global, "los campesinos" siguen presentes. Encontramos, por ello, agroproductores para quienes el cultivo de maíz o frijol para el mercado local o nacional sigue siendo su razón de ser, aunque siembren sólo un par de hectáreas, acomoden en el mercado apenas un par de toneladas de los producido y dejen, de lo levantado, sólo un pequeño "guardadito" para ir gastando en sus unidades de producción mientras vuelven a cosechar.

Otros han dejado de lado su participación en actividades agropecuarias al considerarlas poco "rentables. $\mathrm{Al}$ hacerlo, han optado por "aprender" (rescatando) viejas formas de producir alimentos - aquellos conocidos como "productos artesanales o tradicionales"-. En el ca- so de estos últimos, al igual que su contraparte europea o estadounidense, estas estrategias productivas, en su carácter de re-inventadas a la "Hobsbawm", se ponen en marcha como nuevas ventanas de oportunidad en tanto que nuevos nichos de mercado para productos distintivos (i.e., su singularidad descansa en la diferenciación/especificidad con la que se dota al producto mismo) o para las mercancías agroalimentarias de calidad señaladas en el párrafo anterior. La característica de estos productos es que reciben un valor agregado mayor debido al hecho de que son reconocidos como singulares. Estos productores agropecuarios son algunos de los que apuestan por nuevas formas de hacer agricultura en México. En contraste, muchos otros agroproductores prefieren emplearse como jornaleros en la agricultura de exportación. Otros más migran en busca de trabajo, de mejores oportunidades de empleo, salarios competitivos y dignos, favoreciendo así a diversos sectores de la economía de Estados Unidos. Al marchar, estos actores no entierran el campo, lo mantienen vivo mediante el errático, pero siempre constante, envío de remesas para que sus allegados se mantengan, al menos parcialmente, en las labores y espacios rurales. Finalmente, igual de significativo es reconocer que algunos de nuestros fuertes empresarios agropecuarios han logrado integrar sus cadenas agroindustriales de manera altamente eficaz y siguen siendo igual o más competitivos que sus contrapartes extranjeras.

En suma, la agricultura practicada a cualquier escala se mantiene como una actividad prioritaria para el sector rural del país. La agricultura del México actual es la especializada en granos básicos, la de exportación tradicional, la agricultura empresarial, la agricultura alternativa y aquella dedicada a la ganadería — sin dejar de lado la que se dedica al cultivo de estupefacientes-. Lo es también la agricultura diversificada que practican pequeños y medianos productores, cuyos ingresos se complemen$\tan$ con actividades diferentes a las agropecuarias, llevadas a cabo dentro o fuera del ámbito rural.

Los retos que enfrenta el campo mexicano atienden, por ello, a su particular complejidad, heterogeneidad y creciente inequidad entre individuos, grupos sociales, micro-regiones y regiones; a la dinámica de sus procesos de inclusión/exclusión; a la selectiva y desigual asigna- 
ción de recursos productivos del Estado a grupos diferenciados de productores; a la prioridad que se le ha dado a la promoción de la agricultura de exportación y de alto rendimiento empresarial vis à vis de la poca atención y apoyos financieros y de conocimientos prestados al resto de las actividades agropecuarias que se realizan en el ámbito rural; a la preponderancia que han tenido los programas asistenciales frente a aquellos de corte productivo dirigidos a pequeños y medianos productores; a la agudización del flujo migratorio de la fuerza laboral dentro y fuera del país. Esto implica que dentro de los grandes desafíos del sector agroalimentario a mediano y largo plazo está lograr un desarrollo socialmente incluyente, coparticipativo y corresponsable, en el marco de la globalización neoliberal de nuestro país y de la aproximación del año 2008. Este esfuerzo requiere de la sensibilización tanto del Estado como de la sociedad en relación con la importancia y el significado de este sector para el desarrollo y para imaginar "a la Anderson" la soberanía alimentaria del país (Anderson, 1986: 14-16), así como del reconocimiento y el aprovechamiento de las particularidades, la diversidad y la aguda inequidad que distinguen a las distintas agriculturas que se practican hoy por hoy.

Entender y atender esta pluralidad de desafíos multidimensionales es un reto urgente. Es preciso abordarla desde la perspectiva interdisciplinaria sistémica (diagnóstico, planeación y prospectiva), mediante el diseño y la implementación coparticipativa de estrategias intersectoriales de desarrollo integral, incluyente y social y medioambientalmente respetuoso, que se sustente en el derecho de todos los ciudadanos a la alimentación nutritiva y de calidad. Esta perspectiva debe coadyuvar a construir a corto, mediano y largo plazo mecanismos viables, éticos, justos y dignos de fomento para las distintas agriculturas, las diversas actividades y modos de vida que conforman la sociedad rural hoy.

Esto me lleva a insistir en: a) la propuesta para la introducción de formas de agricultura alternativa, y hacer, al mismo tiempo, b) un llamado a la re-conceptualización y revaloración de nuestras agriculturas y nuestros campesinos por parte de la sociedad y del Estado. Para ello, planteo la necesidad de: 1) bosquejar programas con base en la agricultura diversificada que se da en Mé-

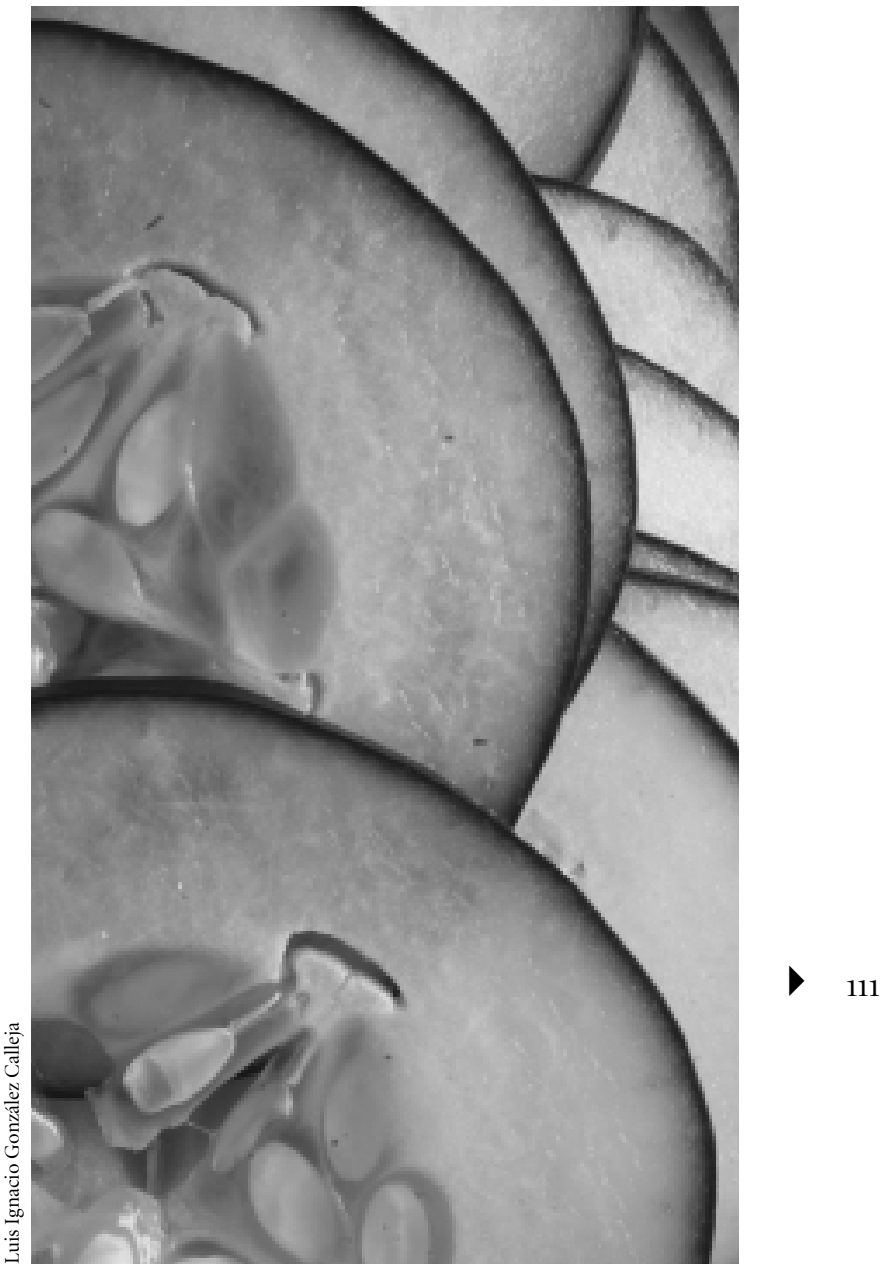

Pepinos.

xico — esto es, la "tradicional" a pequeña y mediana escala, la "inventada a la Hobsbawm" (1983: 1-14), "la de calidad", la de exportación y/o empresarial—; 2) poner atención simultánea a la demanda interna y a la de exportación, partiendo de acciones coparticipativas y corresponsables social y medioambientalmente, con el fin de atender la complementariedad de las actividades agropecuarias, agroindustriales y de servicios. Finalmente, invito a buscar formas eficientes y socialmente incluyentes de incorporar la ciencia y la tecnología a las políticas públicas intersectoriales, ya que las respuestas a los retos que enfrentan los diversos grupos de produc- 
tores ante el quehacer de la globalización neoliberal y de la reconfiguración de la soberanía alimentaria de México va más allá de las competencias de nuestras agriculturas y del sector rural.

Algunas de las vías que propongo para llevar acabo el abordaje de este México rural complejo y marcado por la fluidez de sus múltiples interrelaciones y la construcción de oportunidades para nuestras agriculturas son las siguientes: 1) agricultura convencional, pobreza y narcotráfico; 2) organizaciones de agroproductores; 3 ) migración y remesas; 4) agricultura de exportación y empleo rural; 5) agricultura alternativa; 6) alimentos de calidad, seguridad y soberanía alimentaria; 7) elaboración de leyes que conlleven la soberanía alimentaria sustentada en el derecho de los mexicanos a alimentos de calidad; 8) integración horizontal y vertical de cadenas agroindustriales; 9) fortalecimiento de sistemas agroalimentarios locales y regionales y su vinculación con las especificidades y dinámicas de la demanda urbana diferenciada; 10) desarrollo de mercados locales, regionales y nacionales, con especial énfasis en el fortalecimiento del mercado doméstico; y 11) diseño de programas de corte multisectorial, en los que se involucren distintas instancias del Estado y del sector privado.

Desde fines del siglo pasado a la fecha han empezado a repuntar actividades agropecuarias dentro de lo que denomino "agricultura alternativa". La agricultura alternativa es la que se ocupa de los productos agroalimentarios con denominación de origen, de aquellos que se presentan y reconocen como mercancías orgánicas o como bienes vinculados a nuevas formas de solidaridad consumidor-productor, así como de las mercancías agroalimentarias de calidad vía el seguimiento de normatividades, del respeto a la biodiversidad y/o de la solidaridad de los consumidores hacia los productores de los países en desarrollo. Esta agricultura se lleva a cabo para producir bienes agroalimentarios que materializan la nostalgia por un pasado ya ido o por los quehaceres agroalimentarios artesanales, a los cuales tanto segmentos del mercado doméstico como del global les están abriendo ventanas de oportunidad —sean éstos "productos de la tierra" con sello distintivo o los prosaicos "frijolitos con queso"-
Esta forma de agricultura refleja el carácter multifuncional (que se ha venido acentuando en las últimas décadas) que tiene el ámbito rural, en el que lo agropecuario está lejos de reducirse a la producción primaria. En este tenor cabe señalar que la agricultura alternativa comprende un amplio abanico de actividades (algunas de ellas no relacionadas con los quehaceres agropecuarios) y de usos de la tierra, que van desde las producciones agropecuarias con fines alimentarios y no alimenticios hasta el mantenimiento del medio ambiente. La práctica de esta agricultura debe ser concebida, por tanto, en relación con desarrollos multidimensionales e integrales, tanto micro-regionales como regionales y en complementariedad con lo que se conoce como agricultura tradicional (ya sea la campesina, la empresarial o la de exportación).

Reflexiono sobre la variedad de agriculturas y campesinos que acoge el México rural globalizado a la manera neoliberal. Al hacerlo, cuestiono la concepción de Estado. Los invito a que conceptualicemos el Estado tal como lo propuso Antonio Gramsci: Estado + sociedad civil (1989: 263). Lo hago porque considero que la globalización neoliberal ha transformado al México rural, en particular, y a la sociedad mexicana, en general, de maneras distintas a las que adoptaron formas previas del capitalismo en nuestro país. Esto se ha dado al materializarse y particularizarse cambios mayores centrales en el quehacer del aparato estatal y de nuestra economía, vía la domesticación "local" mediante la apropiación y re-significación de dichas macro transformaciones y, simultáneamente, en lo que se ha llamado el "despertar" de la sociedad civil.

Estos procesos de interconexión y mutua conformación de lo macro y micro no se han dado en el vacío. Son procesos de cambios socioculturales, económicos y políticos a los que la sociedad y el Estado mexicano se han sumado y han contribuido a darles forma y especificidad desde las particularidades, la complejidad, la heterogeneidad, la desigualdad y la disonancia de voces, actores, ideas, quehaceres, relaciones y procesos que les caracterizan.

Es esta concepción de Estado + sociedad globalizados en la línea neoliberal lo que me abre el espacio para hacer un llamado a la necesidad de construir formas múl- 
tiples, más no por ello ajenas al conflicto y a los acomodos, para revalorar la agricultura, resignificar lo nuestro, al tiempo que lo dotamos de calidad y de valor agregado, adecuando las ideas y los criterios de los mercados agroalimentarios y del consumo global. De manera simultánea, apelo a abogar por el reconocimiento de que estos bienes de calidad deben fluir tanto hacia los consumidores internos como hacia los transnacionales.

$\mathrm{Al}$ respecto, y retomando la propuesta de agricultura alternativa antes expuesta, cabe apuntar que desde hace algunos años se observa en ciertos sectores de la sociedad mexicana una tendencia similar a la que se está dando al interior de otras sociedades occidentales u occidentalizadas, en las cuales se afianza y acrecienta tanto la concientización y valorización de la agricultura y de los productos tradicionales o con especificidad no masificada, como la preocupación por encontrar formas que permitan el futuro de una agricultura de granos básicos basada en el derecho de todos los ciudadanos sin distinción a alimentos de calidad; el respeto a la biodiversidad y el cuidado y preservación de nuestro patrimonio biogenético; la equidad social y el desarrollo coparticipativo y corresponsable. Esta preocupación se materializa como la propensión a favor del consumo de "bienes regionales" y "artesanales", ya se trate de granos básicos como de productos de la agricultura alternativa — productos orgánicos, marcas colectivas, comercio justo, denominaciones de origen, entre otros-.

Se está dando también, en el mundo globalizado, un movimiento creciente entre los consumidores, que exige la protección con justicia y solidaridad de los bienes agroalimentarios locales y de sus productores o elaboradores. En México, algunos miembros de la sociedad urbana acuden a un número creciente de tiendas delicatessen, de "tienditas", de carnicerías o de mercados de barrio en busca de productos agropecuarios de origen particular, "tradicionales" o "auténticos", identificados con la historia de un lugar, sus costumbres y sus gustos; o de aquellos que se diferencian de los homogeneizados por la masificación del consumo (i. e., tortillas de maíz blanco o de nopal, diferentes variedades de queso, crema, bebidas espirituosas, tomatillo verde de vara, etc.). El carácter distintivo de estos productos se atribuye a que provienen de áreas ru- rales y han sido manufacturados conforme a "nuestros productos" (el maíz blanco) o a las "viejas formas de elaboración de los productos hechos a mano" (la cajeta) —caracterizados por sus bajos rendimientos y su débil inserción al mercado-. El valor agregado y el prestigio otorgados a estos bienes descansan en la protección de pequeñas comunidades que practican la agricultura en pequeña escala y que fomentan, en muchos casos, la igualdad social. En otras palabras, dentro del capitalismo neoliberal predominante en la sociedad mexicana, lo mismo que en algunos otros sectores sociales del ámbito global, a los alimentos se les está resignificando y revalorando con base en su especificidad local e histórica a medida que se van incorporando en la circulación y consumo global de mercancías, valores e ideas. Tales productos se han convertido en símbolos sociales que significan gusto y origen distintivo y que, con estas características, permiten a ciertos grupos marcar material y simbólicamente su distinción y pertenencia diferencial de clase y de grupo. Esto lo hacen al apostar por un cierto tipo de consumo e ideas renovadas acerca de "lo exótico", lo rural, la tradición, lo distintivamente nuestro. Así, el crecimiento de la demanda de estos productos de la agricultura alternativa reafirma el prestigio socioeconómico y el gusto particular de quienes los producen tanto como de quienes los consumen, al tiempo que informa sobre las concepciones cambiantes de la agricultura, de lo rural, de la naturaleza, del cuerpo y de la salud.

Cierro estas reflexiones haciendo una invitación al Estado y a la sociedad mexicana a que seamos copartícipes y corresponsables del desarrollo integral y sustentable de nuestro campo. Solicito que apostemos por el rescate de nuestras agriculturas y de la soberanía alimentaria de México en el marco de la globalización neoliberal. La apuesta por la promoción complementaria del cultivo de granos básicos, de la agricultura de exportación y de la agricultura alternativa es la de buscar formas de aminorar la migración de mano de obra barata a Estados Unidos y a campos itinerantes de agricultura empresarial, al tiempo que nos damos a la tarea de encontrar maneras de mitigar la pobreza, la precariedad y la inequidad que caracterizan al ámbito rural del país. Es, paralelamente, una apuesta que abre el espacio para que el Estado y la 
sociedad converjan en la lucha a favor de construir: a) el derecho de todos a alimentos de calidad y nutritivos; b) oportunidades de empleo accesibles y equitativas para los distintos agroproductores y sus familias; así como c) condiciones de salud y de vida dignas para los diversos actores del campo y vinculados con él.

Mi preocupación última es hacer un llamado a la necesidad de: 1) realizar estudios sobre la viabilidad sociocultural y económica de nuestras distintas agriculturas y regiones; $y$, con base en ello, 2) poner en práctica proyectos de corte integral, coparticipativos y corresponsables social y medioambientalmente. Propongo que el objetivo de estas acciones conjuntas Estado-sociedad sea la promoción y potenciación de distintas formas de agricultura, las cuales, como complemento a las actividades agropecuarias existentes, actúen como palanca para los desarrollos locales, micro-regionales y regionales en el marco - y no de lado- de la urbanización e industrialización de nuestro país. El fin es que la producción y la promoción de un oferta agroalimentaria más variada y de calidad impacte - al tiempo que reconfigure- un mercado doméstico altamente segmentado y fluido, de forma tal que se abran ventanas de oportunidad para nuestros pequeños y medianos agroproductores de granos básicos o productos tradicionales, sin dejar de lado la agricultura empresarial.

Este llamado a apoyar a nuestras agriculturas lo concibo como una actividad sustentada en la adopción de criterios de calidad, con el fin de asegurar la producción de bienes agroalimentarios inocuos para toda la población. Esta premisa descansa en la convicción de que la certificación oficial (nacional y transnacional) de dicha calidad conlleva el reconocimiento por parte de distintos grupos de consumidores de estos bienes agroalimentarios, dentro y fuera del país, así como del derecho que tenemos todos los mexicanos a consumir alimentos de calidad, independientemente de nuestro poder adquisitivo. Considero que mediante la elaboración, la distribución y el consumo de mercancías provenientes de nuestras agriculturas se pueden ir recuperando y resignificando formas tradicionales de producción o elaboración de productos agroalimentarias, a la par que se promueven y revalorizan los productos agropecuarios locales, regionales y nacionales en distintos ámbitos internos e internacionales. Esto implica llevar a cabo acciones y programas de promoción de "lo nuestro" que tengan como fin la revalorización material, social y simbólica de las diversas formas de agricultura que distinguen a nuestro país hoy así como al espacio rural.

Esto redundará, en primer término, en la soberanía alimentaria de México en concordancia con el derecho al acceso no diferenciado a alimentos de calidad para todos los mexicanos, así como en la no dependencia de nuestro país de los alimentos provenientes de los intercambios desiguales en la arena global. En segundo lugar, lo anterior conllevará la disminución de la migración de mano de obra barata en condiciones de incertidumbre y alto riesgo a Estados Unidos y, con ello, la recuperación de la soberanía laboral (integral) de nuestro país.

\section{Bibliografía}

Anderson, Benedict, 1986, Imagined Communities. Reflections on the Origins and Spread of Nationalism, Thertford Press Limited, Londres.

Blaikie, P., T. Cannon, I. Davis y B. Wisner, 1996, Vulnerabilidad. El entorno social, politico y económico de los desastres, Red de Estudios Sociales en Prevención, Colombia.

Da Silva et al., 2006, "La política de seguridad alimentaria y nutricional de Brasil a partir del Programa Hambre Cero", ponencia presentada en el VII Congreso Latinoamericano de Sociología Rural.

Gramsci, Antonio, 1989, Selections from the Prison Notebooks, International Publishers, Nueva York.

Hobsbawm, Eric, 1983, "Introduction: Inventing Traditions", en Eric Hobsbawm y Terence Ranger, The Invention of Tradition, Cambridge University Press, Cambridge.

Rodríguez Gómez, Guadalupe, 1998, "Relaciones de poder en torno (que dan forma) a la calidad", ponencia presentada como conferencia magistral en el Congreso Anual de LAPEM, Comisión Federal de Electricidad.

__, 2006, El frijol en México. Notas para una agenda de soberanía alimentaria, Universidad de Guadalajara, Guadalajara.

Warman, Arturo, 1976, ... Y venimos a contradecir. Los campesinos de Morelos y el estado nacional, Centro de Investigaciones y Estudios Superiores en Antropología Social, México. 